\title{
CXCR3 Chemokine Receptor Distribution in Normal and Inflamed Tissues: Expression on Activated Lymphocytes, Endothelial Cells, and Dendritic Cells
}

\author{
María Ángeles García-López, Francisco Sánchez-Madrid, \\ Jose Miguel Rodríguez-Frade, Mario Mellado, Agustín Acevedo, M. Isabel García, \\ Juan Pablo Albar, Carlos Martínez-A, and Mónica Marazuela
}

Departments of Endocrinology (MAG-L, MMa), Immunology (FS-M), and Pathology (AA), Hospital de la Princesa, Universidad Autónoma, Madrid, and Department of Immunology and Oncology (JMR-F, MMe, MIG, JPA, CM-A), Centro Nacional de Biotecnología, CSIC, Madrid, Spain

\begin{abstract}
SUMMARY: Using new human CXCR3 chemokine receptor-specific monoclonal antibodies, we studied human CXCR3 tissue distribution in lymphoid and nonlymphoid organs, as well as in inflammatory conditions, including rheumatoid arthritis, Hashimoto's thyroiditis, and dermal vasculitis. CXCR3 was expressed by certain dendritic cell subsets, specifically myeloidderived CD11c positive cells, not only in those present in normal lymphoid organs, but also in germinal centers generated in inflammatory conditions. CXCR3 expression was also detected in some lymphocyte subsets such as intraepithelial lymphocytes of secondary lymphoid organs and infiltrating lymphocytes in inflammatory conditions. In addition, CXCR3 was constitutively expressed by endothelial cells (EC) of vessels of medium and large caliber but not in small vessels from different organs. Finally, enhanced CXCR3 expression was found in EC and in infiltrating lymphocytes with an activated phenotype in inflammatory diseases. The CXCR3 chemokine receptor may play a role in the regulation of leukocyte migration to inflammatory sites. (Lab Invest 2001, 81:409-418).
\end{abstract}

$C$ hemokines are a family of cytokines initially characterized by their capacity to induce chemotaxis, or directed leukocyte migration (Adams and Shaw 1994; Baggiolini 1998). Chemoattractants are postulated to regulate leukocyte traffic into inflammation sites and into lymphoid as well as nonlymphoid tissues during recirculation (Springer, 1994). The chemokines are divided into four subfamilies that differ in their biochemical characteristics and chromosomal localization (Howard et al, 1996). The two major families are termed CXC and CC, according to the presence or absence of an amino acid between a pair of conserved amino terminal cysteine residues. CXC chemokines are functionally diverse; the majority contain the amino acid motif ELR and are potent neutrophil chemoattractants.

Chemokine receptors are single-chain, heptahelical receptors coupled to G proteins (Howard et al, 1996). In humans, nine CC receptors (CCR1-9) and five CXC receptors $(\mathrm{CXC1-5)}$ have been reported, based on

\section{Received December 7, 2000}

This work was supported by grants from the INSALUD (FIS 98/1099), the Spanish National Plan for Science and Technology SAF 99-0034-C0-01, and FEDER 2FD 97-068. Work in the Department of Immunology and Oncology was funded in part by grants from the CICyT and the DGI (Spain). The Department of Immunology and Oncology was founded and is supported by the Spanish Research Council (CSIC) and Pharmacia \& Upjohn.

Address reprint requests to: Dr. Mónica Marazuela, Servicio de Endocrinologia, Hospital de la Princesa, Diego de León 62, Madrid E-28006, Spain. E-mail:monica@marazuela.com their ligand specificity (Baggiolini et al, 1997; Sallusto et al, 1998). Chemokine binding to receptors triggers multiple cell functions; they not only direct migration, but also activate integrin adhesiveness and stimulate degranulation, cell shape change, or actin polymerization (Sánchez-Madrid and Del Pozo, 1999). The specificity of chemoattractants is regulated by the combinatorial distribution of their receptors on the cell surface (Baggiolini et al, 1997; Luster, 1998; Sallusto et al, 1998).

The CXCR3 chemokine receptor signals in response to the CXC chemokines IFN-inducible 10-kDa protein (IP-10), monokine induced by IFN (Mig), IFN-inducible $\mathrm{T}$ cell-chemokine (I-TAC), and in mouse, to the CC chemokine 6Ckine (Cole et al, 1998; Loestcher et al, 1998; Luster et al, 1995; Soto et al, 1998). Although the cellular distribution of CXCR3 has not been studied in detail, its expression appears to be restricted to certain cells of the leukocyte lineage, including activated T cells and natural killer cells (Loestcher et al, 1998; Qin et al, 1998; Sallusto et al, 1998). Recently, it has also been described in a small subset of dendritic cells (DC), plasmacytoid DC (Cella et al, 1999). IP-10 and Mig binding to the CXCR3 receptor are considered important in delivering specific signals for selective homing of activated/effector cells, which accumulate preferentially at certain inflammatory sites (Sallusto et al, 1998).

Using a specific antihuman CXCR3 monoclonal antibody (mAb) and immunohistochemical tech- 
niques, we studied CXCR3 tissue distribution in normal lymphoid and nonlymphoid organs, as well as in inflammatory conditions. We found that CXCR3 is expressed not only by in vivo activated lymphocytes in inflammatory infiltrates, but also in some endothelial cells (EC) as well as in some DC in lymphoid organs. CXCR3 expression by different cell types may constitute an important mechanism, not only in the regulation of leukocyte migration to inflammatory sites, but also in leukocyte homing to lymphoid organs.

\section{Results}

\section{Characterization of CXCR3 Chemokine Receptor-Specific $\mathrm{mAb}$}

Anti-CXCR3 mAb were derived from mice immunized with keyhole limpet hemocyanin (KLH)-coupled synthetic peptides corresponding to the third extracellular loop (amino acids 283 to 301). One hybrid CXCR3-01, $\operatorname{lgM} \kappa \mathrm{C} 5$, showed binding activity in enzyme-linked immunoassay (EIA) using the corresponding peptide, and in flow cytometry analysis of CXCR3-transfected human embryonic kidney (HEK)-293 cells (Fig. 1a), indicating recognition of the sequence in the context of the native protein. No recognition was observed using the mock-transfected cells (Fig. 1a), demonstrating specificity for the CXCR3 receptor. In Western blot analysis, CXCR3-01 also recognized a specific 38-kDa band in CXCR3-transfected HEK-293 cell lysates, whereas no recognition was detected using the mock-transfected HEK-293 cell lysates (Fig. 1b). This band was specifically displaced by the immunizing peptide (283 to 301 ), but not by an irrelevant peptide (Fig. 1b). Moreover, CXCR3-01 recognized the specific 38-kDa band in blasts, but not in peripheral blood mononuclear cells (PBMC) (Fig. 1b). The mAb CXCR3-01 recognized different tumor-infiltrating lymphocytes but not PBMC in flow cytometry analysis (Fig. 1c).

\section{CXCR3 Distribution in Normal Human Tissues}

Immunohistochemical and immunofluorescence studies of tissue sections from several lymphoid and nonlymphoid organs were performed using the CXCR3-01 mAb. Findings are summarized in Table 1. In addition, all studies were performed side by side with the commercial antibody anti-CXCR3 1C6 (Qin et al, 1998). To confirm that CXCR3-01 C5 and 1C6 mAb recognized the same cells, we performed serial staining of the tonsil. We found the same cell distribution with both antibodies (Fig. 2, a and b), although the staining with $1 \mathrm{C} 6$ was weaker at saturation concentrations. Incubation of the CXCR3-01 mAb with the specific peptide abolished the staining (data not shown). Sections immunostained with an IgM isotypematched control mAb with irrelevant specificity did not show any signal (not shown). In addition double staining immunofluorescence studies with CXCR3-01 and $1 \mathrm{C} 6$ confirmed the same pattern of staining (Fig. 3).

Lymphoid Tissues. The CXCR3-01 and 1C6 antiCXCR3 mAb reacted strongly with cells of dendritic

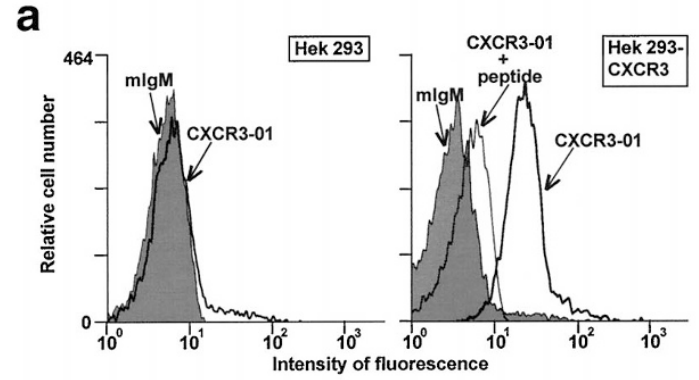

b

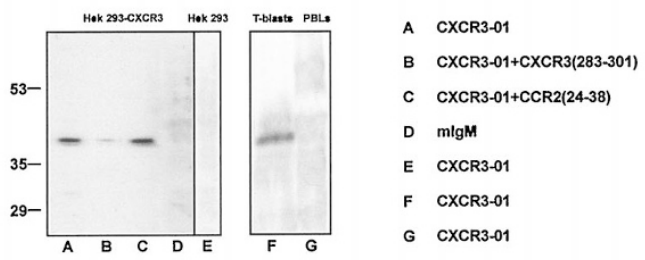

C
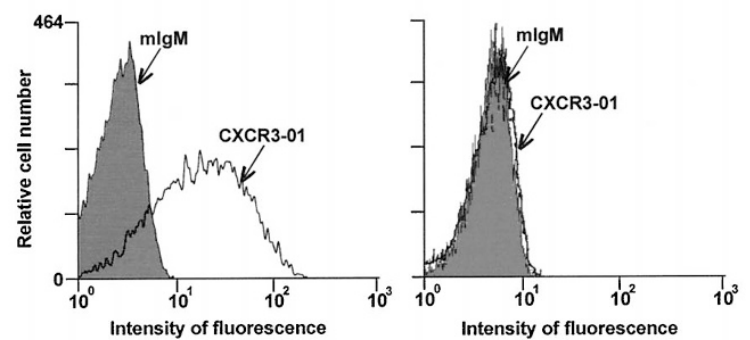

Figure 1

CXCR3-01 antibody specifically recognizes the CXCR3 receptor. a, Human CXCR3 receptor expression analyzed by flow cytometry in CXCR3- or mock-transfected human embryonic kidney (HEK)-293 cells as indicated. Cells were incubated with CXCR3-01 or isotype-matched control (m/gM) mAb, followed by FITC-labeled GAM. Where indicated, the CXCR3-01 mAb was pretreated with the immunizing peptide CXCR3 (283-301), $10 \mu \mathrm{g} / \mathrm{ml}$ in PBS, 30 minutes at $4^{\circ} \mathrm{C}$. b, In Western blot, CXCR3-01 binding to CXCR3transfected HEK-293 cell lysates (lane A) is displaced by the immunizing CXCR3 (283-301) peptide (lane B), but not by the irrelevant peptide CCR2 (24-38) (lane C); as control, an isotype-matched mAb ( $\mathrm{m} / \mathrm{gM}$ ) was used (lane D). Untransfected HEK-293 cell lysates developed with CXCR3-01 were included as negative control (lane E). CXCR3 protein was detected by Western blot from $\mathrm{T}$ blasts (lane F), but not in peripheral blood leukocytes (lane G). C, Human CXCR3 receptor expression analyzed by flow cytometry in tumor infiltrating lymphocytes (left) and in peripheral blood lymphocytes (right). Cells were incubated with CXCR3-01 or isotype-matched control (mlgM) monoclonal antibodies, followed by FITC-labeled GAM. In all cases, one representative experiment of five performed is shown.

morphology in peripheral lymph node and tonsil follicular centers. To assess CXCR3 expression, immunostaining experiments were performed in serial biopsy sections of tonsils with a panel of $\mathrm{mAb}$ against antigens expressed selectively on dendritic/macrophages (DC) and follicular dendritic cells (FDC). CXCR3 expression assessed by immunostaining with both CXCR3-01 and 1C6 mAb was found in DC of the germinal center in the $B$ cell area and also in the paracortical area (Fig. 2, a and b). Coexpression of the CD11c antigen by DC of the germinal center was confirmed in parallel tissue sections with the CD11c antigen (Fig. 2c), as well as by double immunostaining with CD11c (alkaline phosphatase) and CXCR3 (peroxidase) (Fig. 2d). In addition, immunofluorescence 
Table 1. CXCR3 Expression in Lymphoid and Nonlymphoid Organs

\begin{tabular}{|c|c|}
\hline Organ & Expression \\
\hline \multicolumn{2}{|l|}{ Lymph node and tonsil } \\
\hline \multicolumn{2}{|l|}{ B cell area } \\
\hline Lymphocytes & $(-) /+$ \\
\hline Follicular dendritic cells & $(-)$ \\
\hline Dendritic cells & +++ \\
\hline \multicolumn{2}{|l|}{ T cell area } \\
\hline Lymphocytes & $(-) /+$ \\
\hline Interdigitating DC & $(-) /+$ \\
\hline Intraepithelial lymphocytes & +++ \\
\hline Epithelial cells (tonsil) & $(-)$ \\
\hline Macrophages & ++ \\
\hline \multicolumn{2}{|l|}{ Endothelial cells } \\
\hline High endothelial cells & +++ \\
\hline Large vessels & +++ \\
\hline Capillaries & $(-)$ \\
\hline \multicolumn{2}{|l|}{ Thymus } \\
\hline Medullary thymocytes & $(-) /+$ \\
\hline Cortical thymocytes & $(-)$ \\
\hline Epithelial cells & $(-)$ \\
\hline Hassall's corpuscles & $(-)$ \\
\hline Dendritic cells & $(-)$ \\
\hline Macrophages & +++ \\
\hline \multicolumn{2}{|l|}{ Skin } \\
\hline Keratinocytes & $(-)$ \\
\hline Dendritic epidermal cells & $(-)$ \\
\hline Skin appendages & $(-)$ \\
\hline Blood vessels & $(-)$ \\
\hline \multicolumn{2}{|l|}{ Kidney } \\
\hline Tubular epithelium & $(-)$ \\
\hline EC glomerular structures & $(-)$ \\
\hline EC large vessels & +++ \\
\hline Mesangium & ++ \\
\hline \multicolumn{2}{|l|}{ Liver } \\
\hline Hepatocytes & $(-)$ \\
\hline Kupffer cells & +++ \\
\hline Sinusoidal lymphocytes & + \\
\hline Biliary epithelium & $(-)$ \\
\hline Capillaries & $(-)$ \\
\hline \multicolumn{2}{|l|}{ Lung } \\
\hline Alveolar cells & $(-)$ \\
\hline Bronchial cells & $(-)$ \\
\hline Interstitial mononuclear cells & + \\
\hline EC large vessels & +++ \\
\hline
\end{tabular}

studies demonstrated that DC coexpressed CXCR3 (green) and CD11c (red) (Fig. 3c). No CXCR3 expression was observed in FDC (Fig. 2e).

Strong CXCR3 expression was also detected in some EC, as confirmed by immunostaining of parallel tissue sections with the EC-specific antigen factor VIII (Fig. 2f). Positive CXCR3 staining was observed in large- and medium-sized EC (ie, postcapillary venules), in EC of large- and medium-sized vessels of the thymus, lymph node, and tonsil (Fig. 2, a and b insets), but not in small EC. In addition, immunofluorescence studies by double immunostaining with CXCR3 (green) and factor VIII (red) showed coexpres- sion of both antigens by EC (Fig. 3c). However, no expression of CXCR3 protein was found on confluent resting HUVEC cells by Western blot analysis (not shown). In addition, no CXCR3 mRNA was found under basal conditions or after stimulation with any of the stimuli, including $\gamma$-IFN, TNF $\alpha$, and IL- 1 by using the RNAse protection assay (not shown). CXCR4 mRNA positivity found under basal conditions and after stimulation was used as positive control.

In addition, CXCR3 was present in a small fraction of lymphocytes, mainly in the intraepithelial lymphocytes in tonsil (Fig. 2, a and b), as well as on scattered lymphocytes in T cell areas and mantle B cells (Fig. 2, $a$ and b). No reactivity was found on epithelial cells in the tonsil (Fig. 2a). Similar observations were made in lymph node (not shown).

In thymus, CXCR3 was expressed by thymic macrophages. $\mathrm{CXCR}^{+}$staining was also found in some medullary thymocytes, but not in cortical thymocytes (Fig. 4a).

Nonlymphoid Organs. In liver, both hepatocytes and the sinusoid endothelia were negative when stained with the CXCR3-01 mAb. In contrast, EC from large vessels as well as most hepatic Kupffer cells and scattered lymphocytes stained positively with the antiCXCR3 mAb (Fig. 4b). In kidney, EC from large vessels were positive; in the glomeruli, the mesangium showed strong reactivity (Fig. 4c), whereas renal tubular epithelia, including collecting ducts, were negative. In skin, no CXCR3 staining was found in keratinocytes, skin appendages, EC, or Langerhans cells (Fig. 4d). In lung, expression was found in large vessels and some alveolar macrophages, with no expression in bronchial epithelia (not shown).

\section{CXCR3 Expression in Inflammatory Conditions}

Thyroiditis. Up-regulated CXCR3 expression was found in thyroid gland EC from patients with Graves' disease and Hashimoto's thyroiditis, with maximal expression in areas of abundant lymphocytic infiltration (Fig. 5a). Cells positive for CXCR3 were also detected preferentially in perifollicular EC and on EC of small venules, and EC of large vessels (Fig. 5a). Furthermore, CXCR3 was found in mononuclear cells in lymphoid aggregates in patients with Hashimoto's thyroiditis, close to $\mathrm{CXCR}^{+}$EC (Fig. 5a) and in some DC of follicular centers (Fig. 5b).

Dermal Vasculitis. Endothelial CXCR3 expression was detected in vessels (almost exclusively venules) in leukocytoclastic vasculitis. In addition, a population of infiltrating mononuclear cells, including macrophages and lymphoid cells, were found to be $\mathrm{CXCR}^{+}$(Fig. 5c).

Synovitis. CXCR3 was expressed by vascular EC in chronic rheumatoid synovitis. CXCR3 was also found in mononuclear cells in lymphoid aggregates, close to $\mathrm{CXCR3}^{+}$EC (Fig. 5d).

\section{Discussion}

Chemokines play a fundamental role in leukocyte migration, and much effort has therefore been focused 

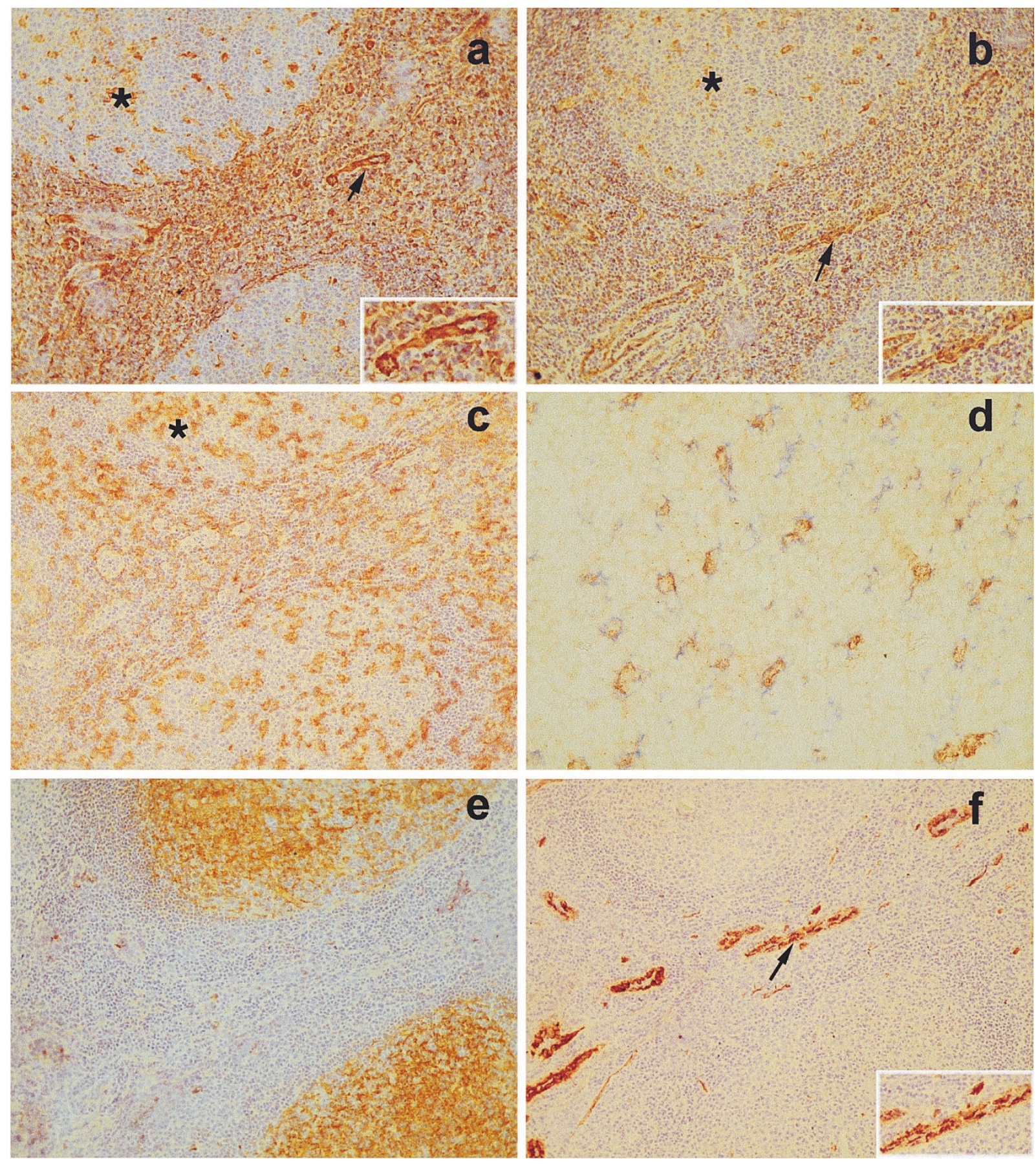

\section{Figure 2.}

Parallel tissue sections of a tonsil for CXCR3-01, CXCR3 1C6, CD11c, anti-DRC-1 mAb, and factor VIII by immunohistochemistry. a, CXCR3 is markedly expressed on dendritic cells (DC) of germinal centers and paracortical areas of a lymphoid follicle (asterisk), in endothelial cells (EC) of large vessels (arrow), and in parafollicular lymphocytes using the CXCR3-01 mAb. Serial sections of the same vessel are included in the small insert for CXCR3 and factor VIII. b, Concordant findings with Panel a using the commercial antibody CXCR3 1C6. c, Parallel staining with CD11c shows most CXCR3 ${ }^{+}$DC (asterisk). d, Double immunostaining for CXCR3 ${ }^{+}$ (brown) and $\mathrm{CD}_{11 \mathrm{c}^{+}}$(blue) demonstrates CXCR3 expression by CD11c ${ }^{+} \mathrm{DC}$ of the germinal center. e, Follicular dendritic cells (FDC) expressing anti-DRC-1. f, Parallel tissue sections of a tonsil for factor VIII shows staining in CXCR3+ EC (arrow). All figures, original magnification, $\times 225$.

on identifying the relevant chemokine receptors expressed by different cell types. Analysis of the precise role of various chemokine receptors has nevertheless been difficult given their promiscuity; each receptor binds several different chemokines and each chemokine can bind to several different receptors. In addition, specific reagents for chemokines and their recep- tors have not been readily available. We obtained a new anti-CXCR3 mAb that recognizes the amino acid sequence 283 to 301 in the third extracellular loop of the receptor. The properties of this $m A b$ include its ability to recognize the CXCR3 receptor under different experimental conditions (flow cytometry, Western blot, and immunohistochemistry) and specificity, as it 


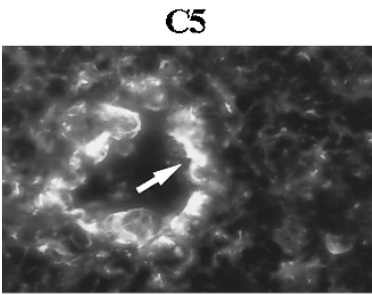

C5

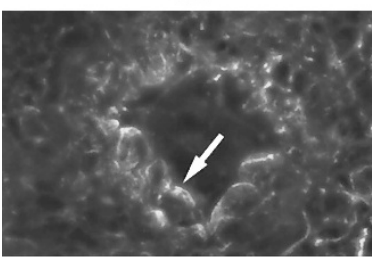

C5

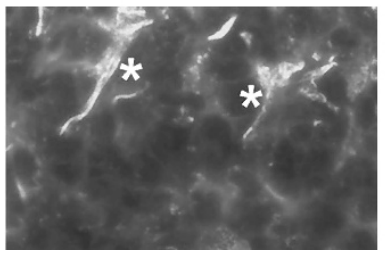

IC-6

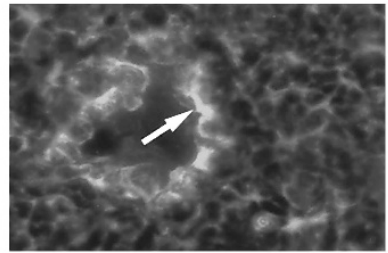

F-VIII

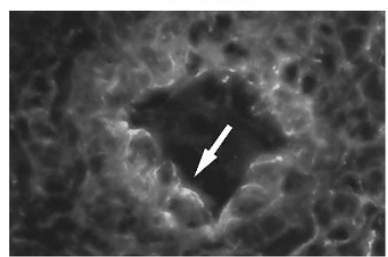

CD11c

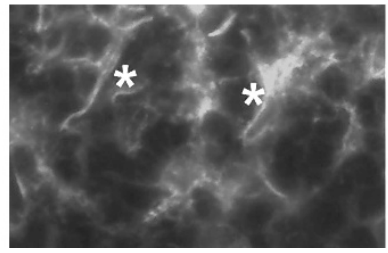

\section{Overlay}

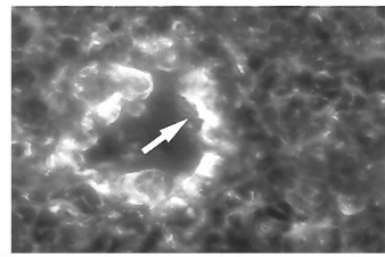

Overlay

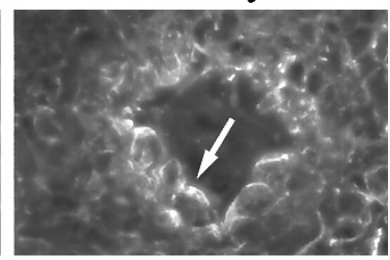

Overlay

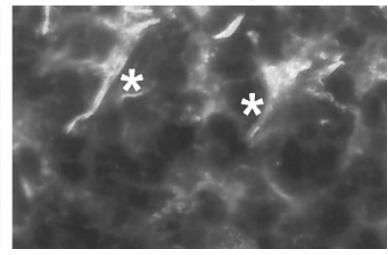

Figure 3.

CXCR3 expression pattern of a tonsil by immunofluorescence. Upper panel: CXCR3-01 (C5) and CXCR3 1C6 colocalize at the same cells (arrows). Middle panel: CXCR3-01 (C5) and factor (F)-VIII demonstrate coexpression in the same vessel (arrows). Lower panel: CXCR3-01 (C5) and CD11C HC1/1 stain the same DC (asterisks).

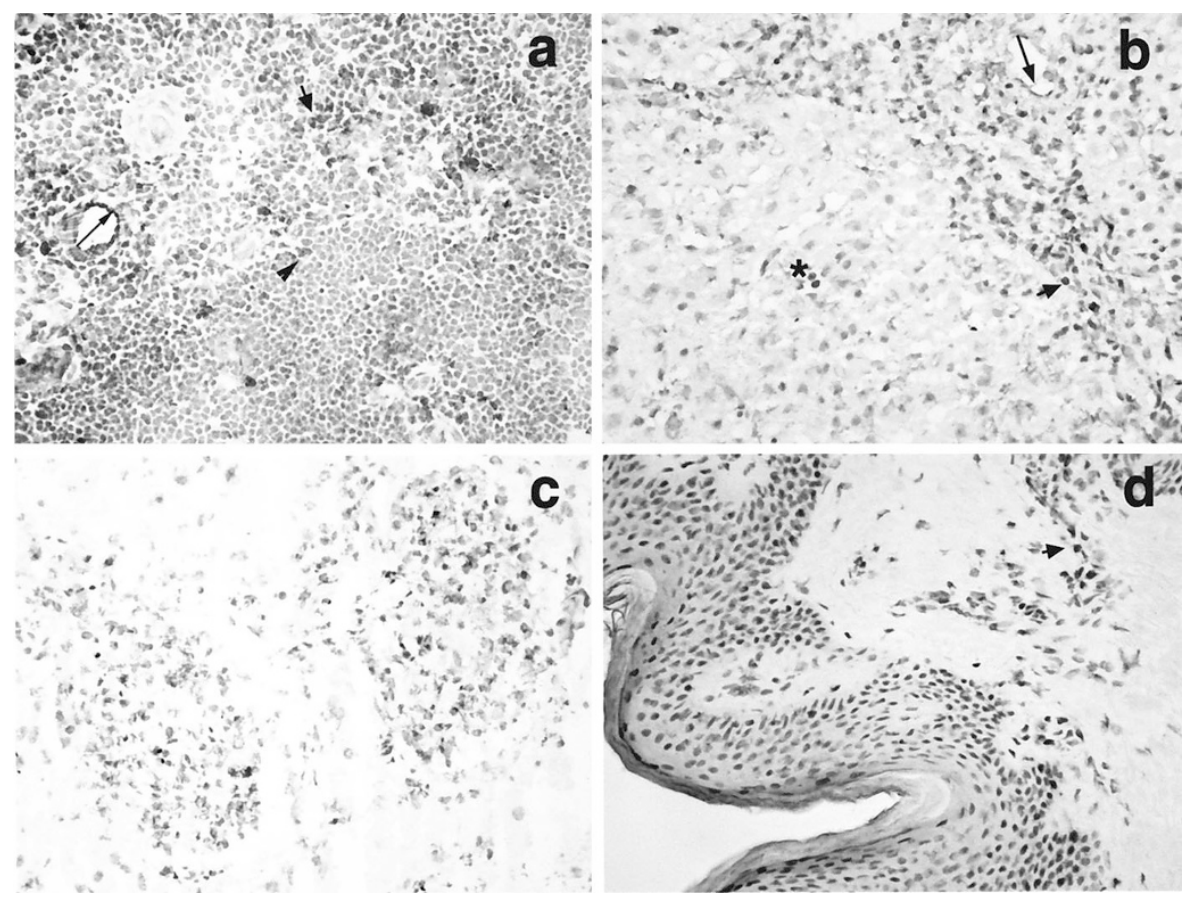

Figure 4.

CXCR3 expression pattern on normal tissues. a, CXCR3 is found predominantly in medullary macrophages and some thymocytes (arrowheads), as well as in EC from large vessels (arrow) (original magnification, $\times 450)$. b, CXCR3 is expressed on Kupffer cells (asterisk), in scattered lymphocytes (arrowhead), and in large vessels (arrow) in the liver (original magnification, $\times 450$ ). c, CXCR3 is expressed by the mesangium in kidney glomeruli (original magnification, $\times 225)$. $d$, No reactivity is found in normal skin except from scattered lymphocytes (arrowhead) (original magnification, $\times 450$ ).

recognizes the receptor in CXCR3-transfected, but not in mock-transfected HEK-293 cells. Staining of various tissues with the anti-CXCR3 mAb revealed that this chemokine receptor is more widely expressed than previously reported, not only in cells of the lymphoid lineage, but also in EC as well as in some DC. 


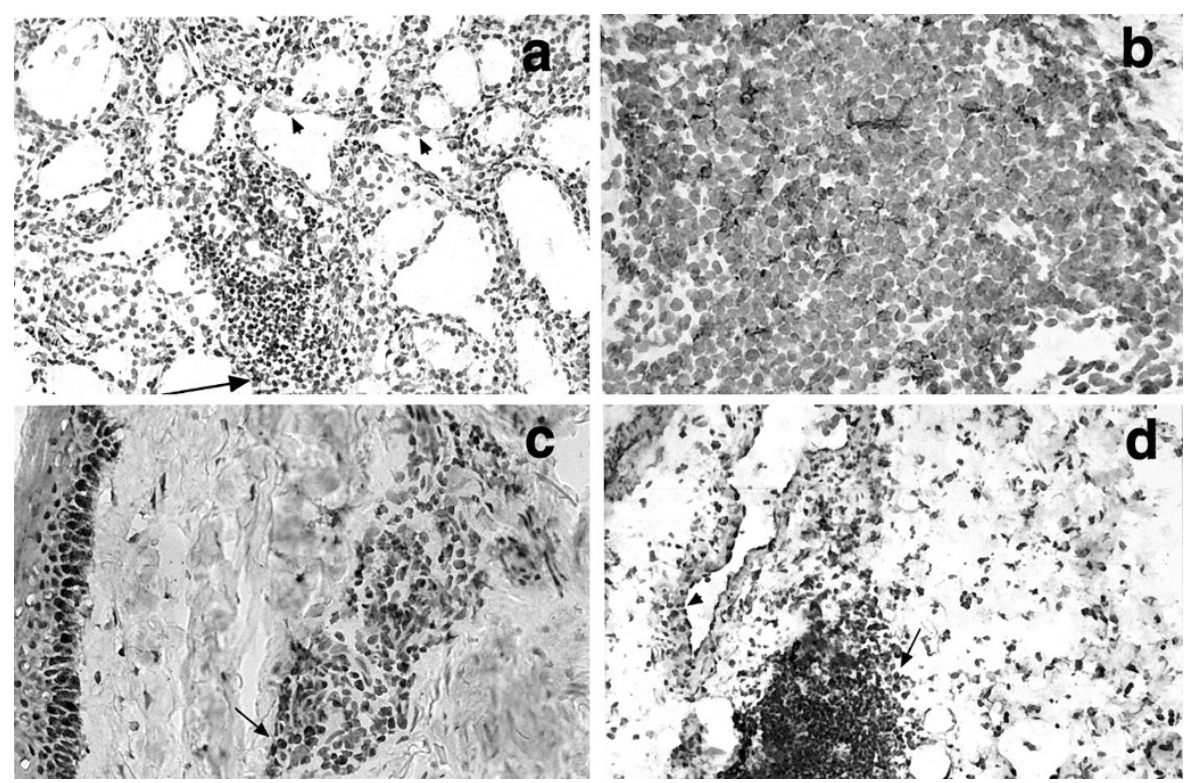

\section{Figure 5.}

CXCR3 expression in patients with Hashimoto's thyroiditis, dermal vasculitis, and rheumatoid arthritis. a, CXCR3 is markedly expressed on infiltrating lymphocytes (arrow) and large EC (arrowheads) (original magnification, $\times 225)$. b, CXCR3 expression in DC of a germinal center from a patient with Hashimoto's thyroiditis (original magnification, $\times 450$ ). c, CXCR3 expression in infiltrating lymphocytes in dermal vasculitis (arrow) (original magnification, $\times 450$ ). $d$, CXCR3 expression on infiltrating lymphocytes (arrow) and large vessels (arrowhead) in rheumatoid arthritis, more evident in more severely inflamed areas (original magnification, $\times 225)$.

In agreement with an earlier report (Qin et al, 1998), we confirmed the presence of the CXCR3 receptor in cells of the lymphoid lineage. In normal lymphoid tissues, CXCR3 was thus located preferentially on medullary thymocytes, as well as on scattered lymphocytes in T cell areas and mantle B cells of secondary lymphoid organs. CXCR3 was also found in intraepithelial lymphocytes and in circulating lymphocytes close to EC. Constitutive CXCR3 expression in lymphoid organs in small subsets of DC, lymphoid cells, and EC may be relevant in the normal trafficking of cells. Lymphocyte recirculation, a critical component of immune surveillance, is facilitated by the ability of antigen-specific lymphocytes to interact with specialized endothelium within secondary lymphoid organs (Butcher and Picker, 1996). Although chemokines trigger the migration of different lymphocyte subsets, their contribution to the physiologic process of lymphocyte homing into lymphoid organs remained unresolved, mainly because chemokines had not been found in normal healthy tissues until very recently (Luster et al, 1995). The expression of CXCR3 in normal lymphoid organs suggests that lymphocyte trafficking into normal secondary and tertiary lymphoid organs may be guided in a fashion similar to leukocyte recruitment to inflammatory lesions (Qin et al, 1998).

Here we describe the detection of CXCR3 in DC. DC are key cells in the immune response, with a central role in antigen-specific immunity (Banchereau and Steinman, 1998; Dieu-Nosjean et al, 1999). DC exert a mobile sentinel function in most tissues where, while immature, they capture antigens. Then they move to the lymphoid organs where they are converted into mature DC prime antigen-specific DC (Banchereau and Steinman, 1998). Chemokines probably play an important role in DC migration and trafficking, because they have been shown to both produce and respond to chemokines (Dieu-Nosjean et al, 1999). Our data showing CXCR3 expression on tonsil and peripheral lymph node DC supports the hypothesis that these cells may migrate to lymphoid organs following chemoattractant signals, as has been described for other chemokines (Dieu-Nosjean et al, 1999). Although the CXCR3 ligand IP-10 was not described to be chemotactic in an in vitro model, other chemokines such as Mig and 6Ckine may interact with CXCR3 in triggering DC migration (Sozzani et al, 1995).

CXCR3 expression was found only in CD11c+ DC of the germinal center, but not in FDC. FDC differ from ordinary $\mathrm{DC}$ in that they are not derived from bone marrow, they lack the leukocyte marker CD45, and they display a unique set of molecules at their surface (CD11b and CD35) (Banchereau and Steinman, 1998). FDC and DC present native antigens to $B$ cells and processed antigens to Thelper cells, respectively. The selective expression of CXCR3 in only one DC type suggests a differential role in the attraction of specific lymphocyte subsets, preferentially activated $\mathrm{T}$ helper cells, to the lymphoid organs; these results concur with the preferential expression of CXCR3 in activated $\mathrm{T}$ cells. In a recent report, CXCR3 was identified in "plasmacytoid monocytes," cells that are found in inflamed lymph nodes around the high endothelial venules (Cella et al, 1999). In contrast, no expression was found in myeloid CD11c+ DC (Cella et al, 1999). Possible explanations for these divergent results could be different monoclonal antibodies used and/or different techniques employed. 
The link between DC traffic pattern and function has led to the investigation of the chemokine responsiveness of DC during their development and maturation. DC subpopulations in lymphoid organs are heterogeneous, one expressing and one lacking CD11c (Grouard et al, 1996; O’Doherty et al, 1994). Although the CD11c-negative subset is functionally immature, the CD11c-positive mature subset has potent T stimulating activity and expresses the activation antigen CD45RO (Grouard et al, 1996; O’Doherty et al, 1994). Activation of DC induces the production of proinflammatory chemokines that induce maturation of immature to mature DC (Melchers et al, 1999). In this process, DC switch their chemokine receptor profile and up-regulate the expression of CCR7 (Sallusto et al, 1999). The in vivo CXCR3 expression in CD11c+ germinal and paracortical mature DC as in germinal centers of autoimmune diseases, and its absence in Langerhans cells, suggests that it could play a role in accumulation of antigen-loaded mature DC.

In contrast to previous reports, we found CXCR3 to be constitutively expressed on EC of some organs as well as in different inflammatory conditions. Reports on the expression of CXCR3 by EC have been conflicting (Feil and Augustin, 1998). Although expression of CXCR-3 mRNA has been found in quiescent, resting HUVEC and microvascular EC (HDMVEC) by RTPCR (Feil and Augustin, 1998), RNA expression has not been confirmed by others using a RNAse protection assay (Salcedo et al, 1999). Although we have found CXCR3 expression in vivo in large- and medium-sized vessels by immunohistochemical techniques, we have not found CXCR3 expression in vitro in resting or activated HUVEC by Western blot. In addition, no RNA expression was found in resting or activated HUVEC using a RNAse protection assay. These divergent results could be related to the specific nature of HUVEC and/or the in vitro conditions employed. The CXC chemokines behave as either angiogenic or angiostatic factors (Arenberg et al, 1997); whereas ELR-containing CXC chemokines are angiogenic, the non-ELR-containing CXC chemokines, including the CXCR3 ligands Mig, IP-10, and 6 Ckine, inhibit the angiogenic effects of other chemokines (Howard et al, 1996). Due to their angiostatic nature, these chemokines may have potential antitumor activity (Luster et al, 1995). The nature of the receptor for these angiostatic chemokines on EC is controversial (Keane et al, 1999). Our findings suggest that the angiostatic effect of non-ELR chemokines may be mediated by the CXCR3 receptor present on EC. These EC may express receptors that retain chemoattractants on the luminal surface, not only preventing them from being washed away by blood flow, but also promoting maximal chemoattractant activity (Campbell et al, 1998) by concentrating proadhesive chemokines on the endothelial lumen. In fact, the presence of several chemokines has been demonstrated on the luminal surface of endothelium (Hubere et al, 1991; Rot, 1992). It has also been suggested that the endothelial chemokine-binding molecules could be heparan sulfate-containing pro- teoglycans, abundantly expressed on the luminal surface of endothelium (Tanaka et al, 1993), which bind IP-10 and PF-4 (Rollins, 1997). In conclusion, chemokine receptor expression on EC would increase the specificity of leukocyte binding to endothelium, because chemokine receptor expression and availability can be tightly regulated at the transcriptional level.

We observed remarkable differences in CXCR3 expression by blood vessel EC in various organs. CXCR3 expression was seen only in small vessels of the normal skin, liver, and kidney, whereas CXCR3 expression was detected in most lymphoid organ vessels. This heterogeneity in the endothelium in different segments of the circulatory tree emphasizes the heterogeneity of EC in blood vessels of similar type and caliber from distinct anatomical sites, and may provide clues to functional variation in cell recruitment to different organs. These results concur with previous studies describing a different IL-8 binding pattern to EC in different blood vessels (Rot et al 1996).

Finally, enhanced CXCR3 expression in mononuclear cells, DC, and vascular endothelium in inflammatory conditions such as thyroiditis, rheumatoid arthritis, or dermal vasculitis probably reflects a role for this receptor in the trafficking of activated lymphocytes to the inflammatory foci. Leukocyte extravasation and trafficking into tissues is a tightly regulated process in which chemotactic factors have a major role (Springer, 1994). Elaboration of chemokines by sentinel cells at an inflammatory focus may be responsible for inducing strong adhesive interactions between rolling leukocytes and the endothelium (Gupta et al, 1998). Diapedesing cells are then attracted to the inflammatory site by the chemokine concentration gradient (Nelken et al, 1991). In addition, rapid DC recruitment is a hallmark of inflammation (Sozzani et al, 1995); it is possible that chemotactic signals may also contribute to the rapid DC accumulation observed in inflammation and certain autoimmune conditions. IP-10 and Mig, the chemokines that interact with CXCR3, are considered important signals for selective homing of activate/effector cells, which preferentially accumulate in some inflammatory sites (Sallusto et al, 1998). Once T cells gain entry to a tissue, IP10/Mig-CXCR3 interaction may also be important in the positioning of effector T cells. High IP-10 levels have been detected in areas of chronic inflammation (Gottlieb et al, 1988). Altogether, our results indicate that CXCR3 receptor expression may play a critical role in regulating the migration of leukocyte cells, both in physiology and pathology.

\section{Materials and Methods}

\section{Preparation of Anti-CXCR3 mAb}

A peptide was synthesized of the CXCR3 receptor third extracellular loop (amino acid sequence 283 to 301), coupled to KLH (Calbiochem, La Jolla, California) and used to immunize mice, as previously described (Harlow and Lane, 1988; Mellado et al, 1998). Spleen and/or lymph node cells from immunized mice were 
fused with the $\mathrm{P} 3 \times 63-\mathrm{Ag} 8.653$ myeloma cell line $(\mathrm{CRL}$ 1580; American Type Culture Collection [ATCC], Manassas, Virginia) following standard protocols. Supernatants were tested for antibodies in EIA and positive hybridomas cloned by limiting dilution. Isotypes were determined in EIA using peroxidase (PO)-labeled, subclass-specific antimouse immunoglobulin antibody (Southern Biotechnologies Associates, Birmingham, Alabama). Monoclonal antibodies were purified by ammonium sulfate precipitation (Mellado et al, 1997) and/or chromatography on Sephacryl S-200 (Pharmacia, Uppsala, Sweden). In addition the monoclonal antibody anti-CXCR3 mAb 1C6 (Ig G1) (Qin et al, 1998) (PharMingen, San Diego, California) was used as control.

Other mAb used were HC1/1 anti-CD11 (IgG1) (Postigo et al, 1994), anti-DRC-1 (DAKO, Glostrup, Denmark), anti-FVIII (DAKO), and anti-CD43 HP2/21 (IgM) (Serrador et al, 1998). Different isotype-matched irrelevant $\mathrm{mAb}$, mouse IgG1 P3 $\times 63 \mathrm{mAb}$, and mouse IgM MOPC 104E mAb (Sigma Chemical, St. Louis, Missouri) were used as negative controls.

\section{Antibody Capture EIA}

EIA was performed as previously described (Mellado et al, 1997); briefly, synthetic peptide (3 $\mu \mathrm{g} / \mathrm{ml}$ in PBS, $100 \mu \mathrm{l} /$ well) was adsorbed to microtiter plates (MaxiSorb, Nunc, Denmark) after blocking. mAb were incubated and the reaction developed using a PO-labeled goat antimouse immunoglobulin antibody (GAM-PO; Tago, Burlingame, California) and OPD (Sigma).

\section{Cells and Tissues}

Human embryonic kidney (HEK-293) cells (ATCC TIB202) were obtained from the ATCC. Tumorinfiltrating lymphocytes were provided by Dr. P. Sánchez-Mateos (Dept Inmunología, Hospital Gregorio Marañón, Madrid, Spain). Resting PBMC were isolated from fresh human blood by Ficoll-Hypaque density gradient centrifugation (Pharmacia). HUVEC were isolated as previously described (Yañez-Mó et al, 1998) and then incubated for 24 and 72 hours with $\gamma$-IFN (100 U/ml), TNF $\alpha(20 \mathrm{ng} / \mathrm{ml})$, and IL-1 $\beta$ (20 $\mathrm{ng} / \mathrm{ml})$.

Human tonsils were obtained from children undergoing tonsillectomy, and normal thymuses were from children undergoing open heart surgery. Normal samples of spleen, lymph nodes, lung, liver, kidney, thyroid, and skin were from adult patients who had undergone exploratory or therapeutic surgery. All patients gave informed written consent.

\section{Transfection}

HEK-293 were transfected with the CXCR3 c-DNA construct by calcium phosphate precipitation. Transfected cells were selected in G-418 (Calbiochem) and analyzed by flow cytometry for receptor expression using anti-CXCR3 antibodies and IP-10-induced $\mathrm{Ca}^{2+}$ mobilization assays following procedures previously described (Frade et al, 1997)

\section{Flow Cytometry}

PBMC, tumor-infiltrating lymphocytes, and mock- or CXCR3-transfected HEK-293 cells were centrifuged (250 $\times g, 10$ minutes, at room temperature), plated in V-bottom 96-well plates $\left(2.5 \times 10^{5}\right.$ cells/well), and incubated with $50 \mu \mathrm{l} /$ well of undiluted supernatants for 60 minutes at $4^{\circ} \mathrm{C}$. Cells were washed twice with PBS containing $2 \%$ BSA and $2 \%$ FCS (staining PBS) by centrifugation $\left(250 \times g, 5\right.$ minutes, $\left.4^{\circ} \mathrm{C}\right)$. Fluorescein isothiocyanate-labeled goat antimouse IgM (GAMFITC) was added, incubated (30 minutes, $4^{\circ} \mathrm{C}$ ), and plates washed twice. Cell-bound fluorescence was performed using a Profile XL flow cytometer (Coulter, Hialeah, Florida).

\section{Immunohistochemical Staining of Human Tissue Sections}

Cryostat sections were prepared from snap-frozen tissue embedded in OCT medium (Ames, Miles Laboratories, Elkhart, Indiana) and stored at $-80^{\circ} \mathrm{C}$. The tissue sections were stained by an indirect immunoperoxidase method as previously described (Marazuela et al, 1994). Briefly, 5- $\mu \mathrm{m}$ acetone-fixed sections were sequentially incubated with mAb culture supernatants and $\mathrm{PO}$-conjugated rabbit antimouse Ig (DAKO). Each incubation was followed by three washes with Tris-buffered saline (Tris) isotonic buffer, $\mathrm{pH}$ 7.6; sections were then developed with GrahamKarnovsky medium containing $0.5 \mathrm{mg} / \mathrm{ml}$ of $3,3^{\prime}-$ diaminobenzidine tetrahydrochloride (DAB) (Sigma) and hydrogen peroxide. Sections were counterstained with Carazzi's hematoxylin, dehydrated, and mounted by routine methods.

For double immunostaining, after development of the DAB reaction, sections were saturated with nonspecific mouse Ig from the $\mathrm{P} 3 \times 63$ myeloma line, washed, and incubated with the second monoclonal antibody under the same conditions. Sections were subsequently incubated with rabbit antimouse lgG (DAKO), followed by a third incubation with the alkaline phosphatase antialkaline phosphatase complex (DAKO). Each incubation was followed by three washes with Tris. Finally, the alkaline phosphatase reaction was developed by incubating the sections with a Tris $\mathrm{HCl}(50 \mathrm{mmol} / \mathrm{l}, \mathrm{pH}$ 8.4) buffer solution containing $0.2 \mathrm{mg} / \mathrm{ml}$ naphthol AS-MX phosphate (Sigma) and $1 \mathrm{mg} / \mathrm{ml}$ Fast Blue salt (Sigma) with $10^{-5} \mathrm{~mol} / \mathrm{l}$ levamisole as endogenous alkaline phosphatase inhibitor. The reaction product was a bright blue precipitate that contrasted with the brown color of the DAB reaction. Sections were mounted in buffered gelatin for microscopic examination. Each section was examined under code by two independent observers. Sequential sections were used to study cell distribution.

For immunofluorescence microscopy, slides were incubated with the primary antibody and then incubated with the FITC-conjugated sheep antimouse IgG secondary antibody (DAKO). Specimens were examined with a Nikon Labophot-2 with $60 \times$ and $100 \times$ oil immersion objectives. Images were taken with a Cohu high-performance CCD camera (Cohu, Tokyo, Japan) coupled to the microscope and connected to a Leica 
Q550CW workstation. Images were visualized, processed, and stored by using the Leica Qfish software version 1.01 (Leica Imaging Systems, Cambridge, United Kingdom).

\section{SDS-PAGE and Western Blot Analysis}

Mock- or CXCR3-transfected HEK-293 cells $\left(2 \times 10^{7}\right.$ cells) or PBMNC or $\mathrm{T}$ cell blasts were lysed in a detergent buffer (20 mM triethanolamine, $\mathrm{pH} 8.0,300$ $\mathrm{mm} \mathrm{NaCl}, 2$ mм EDTA, 20\% glycerol, 1\% digitonin, with protease inhibitors) for 30 minutes at $4^{\circ} \mathrm{C}$ with continuous rocking, then centrifuged $(15,000 \times g, 15$ minutes). Protein extracts were separated in sodium dodecyl sulfate polyacrylamide gel electrophoresis (SDS-PAGE) and transferred to nitrocellulose membranes. Western blot analysis was performed as previously described (Mellado et al, 1998), using 10\% non-fat dry milk in TBS as a blocking agent. After washing with PBS, the membrane was incubated with $\mathrm{mAb}$ with agitation for 120 minutes at room temperature, followed by GAM-PO (1/5,000 dilution). The reaction was developed using ECL (Amersham, Aylesbury, United Kingdom). Protein loading was controlled in all cases using a protein detection kit (Pierce, Rockford, Illinois).

\section{RNAse Protection Assay}

Total RNA was extracted from HUVEC cells using ULTRASPEC (Biotex Laboratories, Houston, Texas). Multiprobe template set hCR6 (containing DNA templates for CXCR1, CXCR2, CXCR3, CXCR4, Burkitt's lymphoma receptor [BLR]-1, BLR-2/CCR7, V28, and GAPDH) was purchased from PharMingen. The DNA templates were used to synthesize the a-[32P]UTP (3000 Ci/mmol, $10 \mathrm{mCi} / \mathrm{ml}$; Amersham)-labeled probes in the presence of a GACU pool using a T7 RNA polymerase (PharMingen). Hybridization with 5 to $15 \mu \mathrm{g}$ of each target RNA was performed overnight, followed by digestion with RNAse A according to the PharMingen standard protocol. The samples were treated by proteinase K-SDS mixture and then extracted and precipitated in the presence of ammonium acetate. The samples were loaded on an acrylamideurea sequencing gel next to labeled DNA molecular weight markers and to the labeled probes, and run at 50 watts with $0.5 \mathrm{X}$ Tris-borate/EDTA electrophoresis buffer. The gel was adsorbed to filter paper, dried under vacuum, and exposed on film (X-AR; Kodak, Rochester, New York) with intensifying screens at $-70^{\circ} \mathrm{C}$.

\section{Acknowledgements}

We are indebted to A. M. Martín de Ana for technical help. We thank C. Mark for editorial assistance.

\section{References}

Adams DH and Shaw S (1994). Leucocyte-endothelial interactions and regulation of leucocyte migration. Lancet 343: 831-836.
Arenberg DA, Polverini PJ, Kunkel SL, Shanafelt A, Hesselgesser J, Horuk R, and Strieter RM (1997). The role of CXC chemokines in the regulation of angiogenesis in no-small cell lung cancer. J Leukoc Biol 62:554-562.

Baggiolini M (1998). Chemokines and leukocyte traffic. Nature 392:565-568.

Baggiolini M, Dewald B, and Moser B (1997). Human chemokines: An update. Annu Rev Immunol 15:675-705.

Banchereau J and Steinman RM (1998). Dendritic cells and the control of immunity. Nature 392:245-252.

Butcher EC and Picker LJ (1996). Lymphocyte homing and homeostasis. Science 272:60-66.

Campbell JJ, Hedrick J, Zlotnik A, Siani MA, Thompson DA, and Butcher EC (1998). Chemokines and the arrest of lymphocytes rolling under flow conditions. Science 279:381384.

Cella M, Jarrossay D, Facchetti F, Alebardi O, Nakajima $H$, Lanzavecchia A, and Colonna M (1999). Plasmacytoid monocytes migrate to inflamed lymph nodes and produce large amounts of type I interferon. Nat Med 5:919-923.

Cole KE, Strick CA, Paradis TJ, Ogborne KT, Loetscher M, Gladue RP, Lin W, Boyd JG, Moser B, Wood DE, Sahagan $B G$, and Neote K (1998). Interferon-inducible T cell chemoattractant (I-TAC): A novel non-Glu-Leu-Arg (ELR) CXC chemokine with potent activity on activated $T$ cells through selective high affinity binding to CXCR3. J Exp Med 187:2009-2021.

Dieu-Nosjean MC, Vicari A, Lebecque S, and Caux C (1999). Regulation of dendritic cell trafficking: A process that involves participation of selective chemokines. J Leukoc Biol 66:252-262.

Feil C and Augustin HG (1998). Endothelial cells differentially express functional CXC-chemokine receptor-4 (CXCR-4/ fusin) under the control of autocrine activity and exogenous cytokines. Biochem Biophys Res Commun 247:38-45.

Frade JM, Mellado M, del Real G, Gutierrez-Ramos JC, Lind P, and Martínez-A C (1997). Characterization of the CCR2 chemokine receptor: Functional CCR2 receptor expression in B cells. J Immunol 159:5576-5584.

Gottlieb AB, Luster AD, Postnett DN, and Carter DM (1988). Detection of a $\gamma$ interferon-induced protein IP-10 in psoriatic plaques. J Exp Med 168:941-948.

Grouard G, Durand I, Filguera I, Banchereau I, and Liu YI (1996). Dendritic cells capable of stimulating $T$ cells in germinal centres. Nature 384:364-367.

Gupta SK, Lysko PG, Pillarisetti K, Ohlstein E, and Stadel JM (1998). Chemokine receptors in human endothelial cells: Functional expression of CXCR4 and its transcriptional regulation by inflammatory cytokines. J Biol Chem 273:42824287.

Harlow E and Lane D, editors (1988). Storing and purifying antibodies. In: Antibodies: A laboratory manual. New York: Cold Spring Harbor Press, 298.

Howard OM, Ben-Baruch A, and Oppenheim JJ (1996). Chemokines: Progress toward identifying molecular targets for therapeutic agents. Trends Biotechnol 14:46-51.

Hubere AR, Kunkel SL, Todd RF III, and Weiss SJ (1991). Regulation of transendothelial neutrophil migration by endogenous interleukin-8. Science 254:99-102. 
Keane MP and Strieter RM (1999). The role of CXC chemokines in the regulation of angiogenesis. Chem Immunol 72:86-101.

Loestcher M, Loetscher P, Brass N, Meese E, and Moser B (1998). Lymphocyte-specific chemokine receptor CXCR3: Regulation, chemokine binding and gene localization. Eur J Immunol 28:3696-3705.

Luster AD (1998). Chemokines: Chemotactic cytokines that mediate inflammation. N Engl J Med 338:436-445.

Luster AD, Greenberg SM, and Leder P (1995). The IP-10 chemokine binds to a specific cell surface heparan sulfate site shared with platelet factor 4 and inhibits endothelial cell proliferation. J Exp Med 182:219-231.

Marazuela M, Postigo AA, Acevedo A, Díaz-González F, Sánchez-Madrid F, and Landázuri MO (1994). Adhesion molecules from the LFA-1/ICAM.1,3 and VLA-4/VCAM-1 pathways on $T$ lymphocytes and vascular endothelium in Graves' and Hashimoto's thyroid glands. Eur J Immunol 24:2483-2490.

Melchers F, Rolink AG, and Schaniel C (1999). The role of chemokines in regulating cell migration during humoral immune responses. Cell 99:351-354.

Mellado M, Kremer L, Mañes S, Martínez-A C, and Rodríguez-Frade JM (1997). Characterization of antigenantibody and ligand-receptor interactions. In: Lefkovits I, editor. Immunological methods manual. San Diego: Academic Press Ltd, 1145.

Mellado M, Rodríguez-Frade JM, Aragay AM, del Real G, Vila-Coro A, Martin de Ana A, Serrano A, Mayor F Jr, and Martínez-A C (1998). The chemokine MCP-1 triggers tyrosine phosphorylation of the CCR2B receptor and the JAK2/STAT3 pathway. J Immunol 161:805-813.

Nelken NA, Coughlin SR, Gordon D, and Wilcox JN (1991). Monocyte chemoattractant protein-1 in human atheromatous plaques. J Clin Invest 88:1121-1127.

O'Doherty U, Peng M, Gezelter S, Swiggard WJ, Betjes M, Bhardwaj N, and Steinman RM (1994). Human blood contains two subsets of dendritic cells, one immunologically mature and the other immature. Immunology 82:487-493.

Postigo AA, Marazuela M, Sánchez-Madrid F, and Landázuri MO (1994). B lymphocyte binding to $E$ - and P-selectins is mediated through de novo expression of carbohydrates on in vitro and in vivo activated human B cells. J Clin Invest 94:1585-1596.

Qin S, Rottman JB, Myers P, Kassam N, Weinblatt M, Loetshcer M, Koch AE, Moser B, and Mackay CR (1998). The chemokine receptors $\mathrm{CXCR} 3$ and CCR5 mark subsets of $T$ cells associated with certain inflammatory reactions. J Clin Invest 101:746-754.

Rollins BJ (1997). Chemokines. Blood 90:909-928.

Rot A (1992). Endothelial cell binding of NAP-1/IL-8: Role in neutrophil emigration. Immunol Today 13:291-294.
Rot A, Hub E, Middleton J, Pons F, Rabeck C, Thierer K, Wihtle J, Wolff B, Zsak M, and Dukor P (1996). Some aspects of IL-8 pathophysiology III: Chemokine interaction with endothelial cells. J Leukoc Biol 59:39-44.

Salcedo R, Wasserman K, Young HA, Grimm MC, Howard OM, Anver MR, Kleinman HK, Murphy WJ, and Oppenheim JJ (1999). Vascular endothelial growth factor and basic fibroblast growth factor induce expression of CXCR4 on human endothelial cells: In vivo neovascularization induced by stromal-derived factor-1alpha. Am J Pathol 154:11251135.

Sallusto F, Lanzavecchia A, and Mackay CR (1998). Chemokines and chemokine receptors in T-cell priming and Th1/ Th2-mediated responses. Immunol Today 19:568-574.

Sallusto F, Palermo B, Lenig D, Miettinen M, Matikainen S, Julkunen I, Forster R, Burgstahler R, Lipp M, and Lanzavecchia A (1999). Distinct patterns and kinetics of chemokine production regulate dendritic cell function. Eur $\mathrm{J}$ Immunol 29:1617-1625.

Sánchez-Madrid F and Del Pozo MA (1999). Leukocyte polarization in cell migration and immune interactions. EMBO J 18:501-511.

Serrador JM, Nieto M, Alonso-Lebrero JL, Del Pozo MA, Calvo J, Furthmayr H, Schwartz-Albiez R, Lozano F, González-Amaro R, Sánchez-Mateos P, and SánchezMadrid P (1998). CD43 interacts with moesin and ezrin and regulated its redistribution to the uropods of $T$ lymphocytes at the cell-cell contacts. Blood 91:4632-4644.

Soto H, Wang W, Strieter RM, Copeland NG, Gilbert DJ, Henkins NA, Hedrick $H$, and Zlotnik A (1998). The CC chemokine 6Ckine binds the CXC chemokine receptor CXCR3. Proc Natl Acad Sci USA 95:8205-8210.

Sozzani S, Sallusto F, Luini W, Zhou D, Piemonti L, Allavena $\mathrm{P}$, Van-Damme J, Valitutti S, Lanzavecchia A, and Mantovani A (1995) Migration of dendritic cells in response to formyl peptides, C5, and a distinct set of chemokines. J Immunol 155:3292-3295.

Springer TA (1994). Traffic signals for lymphocyte recirculation and leukocyte emigration: The multistep paradigm. Cell 76:301-314.

Tanaka Y, Adams DH, and Shaw S (1993). Proteoglycans on endothelial cells present adhesion-inducing cytokines to leukocytes. Immunol Today 14:111-115.

Yañez-Mó M, Alfranca A, Cabañas C, Marazuela M, Tejedor R, Ursa MA, Ashman LK, Landázuri MO, and SánchezMadrid F (1998). Complexes of tetraspan molecules CD151/ PETA-3, CD9 and CD81/TAPA- 1 with $\alpha 3 \beta 1$ integrin are localized at endothelial lateral junctions and regulate cellular motility. J Cell Biol 141:791-804. 